Esta revista forma parte del acervo de la Biblioteca Jurídica Virtual del Instituto de Investigaciones Jurídicas de la UNAM

\title{
DERECHO DE LA COMUNICACIÓN. GUÍA JURÍDICA PARA PROFESIONALES DE LOS MEDIOS
}

\author{
Arturo APARICIO VELÁZQUEZ*
}

Vivimos en un mundo en el que las sociedades avanzan y evolucionan con las tecnologías, un mundo donde la información y la comunicación de ésta cumple un papel fundamental para el desarrollo de la ciencia, la tecnología, el arte, la política y la sociedad en general. A partir de todo lo que engloba el derecho de la comunicación, se generan cambios estructurales en las políticas públicas, en el actuar de los gobernantes y de los gobernados. Los medios masivos de comunicación cumplen un papel fundamental en el desarrollo de las democracias en el mundo; la imparcialidad e independencia en el desempeño de su actuar informativo es esencial, sobre todo para el trabajo periodístico.

A partir del siglo XXI, con la era del Internet, el boom de las tecnologías en materia de comunicación y las redes sociales, el trabajo periodístico y de los medios de comunicación se transforma indudablemente, y no sólo se reduce a la prensa escrita en papel, radio y televisión, sino que el fenómeno de comunicación es mucho más complejo. Año con año esta realidad cambia a partir del desarrollo de nuevas tecnologías y nuevas redes sociales, lo que obliga a los gobiernos y organismos internacionales a sentarse y dialogar, generando acuerdos para regular todo este espectro de la comunicación, sin dejar a un lado la reflexión de los derechos que hay que salvaguardar.

La necesidad de obtener, por parte de la población, información veraz y crítica obliga a todos aquellos profesionales de la información a conocer,

* Licenciado en derecho por la Facultad de Derecho de la UNAM; asistente de investigación en el Instituto de Investigaciones Jurídicas de la UNAM, arturoapariciov@gmail.com. 
Esta revista forma parte del acervo de la Biblioteca Jurídica Virtual del Instituto de Investigaciones Jurídicas de la UNAM

entender y velar de alguna forma por los derechos que integran el derecho de la comunicación y el régimen jurídico de todo lo que engloba el tema.

Cuando hablamos del derecho de la comunicación, así como lo hacemos al referirnos al derecho de la información, no nos referimos al derecho de ser informados y poder comunicar la información, sino a todos sus derechos conexos y a los problemas de la información y la comunicación inherentes a la actividad periodística y comunicativa. Al abordar todos estos temas nos encontramos con derechos humanos que han ido ganado terreno en las Constituciones de los países del mundo, como lo es la libertad de expresión, el derecho de réplica, el derecho a la información, los límites a éstos, el derecho a la intimidad, a la privacidad, a la imagen, a los menores frente a los medios de comunicación, los derechos referidos en particular a aquellos que realizan actividades periodísticas y de comunicación, el derecho de autor y/o propiedad intelectual, el régimen jurídico de éstos, la regulación de los medios masivos de comunicación y el Internet, así como el de la publicidad.

Como podemos observar, conocer de todo esto, o por lo menos entenderlo, es una tarea obligatoria para los que se dedican a medios, no sólo desde el ámbito jurídico, como lo es un abogado cuando asesora o lleva todo lo relacionado con el tema legal de un canal de televisión, una radio, un sitio web o una revista, sino también es indispensable para el periodista, para el conductor de un programa, el director de un área de una emisora de radio o el que lleva una revista, por grande o pequeña que sea, ya que su actuar debe velar siempre por que se garanticen los derechos de las personas y se realice el desempeño del trabajo de manera legal y regular.

Respecto a todo lo señalado, es necesario que los profesionales de los medios se capaciten en el tema de derechos de la comunicación; sin embargo, al evolucionar año con año la tecnología y con esto el tema de derechos, su legislación al respecto va sufriendo cambios también. Sumando a todo lo anterior que el régimen jurídico en cada país varia y su regulación se encuentra contenida en diversos ordenamientos normativos, nos resulta casi imposible hacerse de todo este conocimiento de forma práctica.

A pesar de que actualmente es sumamente complicado encontrar obras que compilen de manera efectiva todo el material relacionado con el derecho de la comunicación, en el que se señale cada derecho conexo a éste de manera detallada, clara, organizada y actualizada, la reconocida académica Ana Azurmendi lo hace con su libro Derecho de la comunicación. Guía jurídica para profesionales de los medios. Aunque el libro se centra en el fenómeno europeo, especialmente en las resoluciones del Tribunal Europeo de Derechos Humanos y la influencia de éstas en la le- 
Esta revista forma parte del acervo de la Biblioteca Jurídica Virtual del Instituto de Investigaciones Jurídicas de la UNAM

gislación española, me atrevo a decir que la obra no sólo es útil para el que vive en España, sino también es un trabajo que sirve como referente para el desarrollo de obras similares en otros países y es útil para el estudioso del derecho de la comunicación en el desarrollo de trabajos de investigación de derecho comparado.

Sin duda, como bien lo señala el título del libro, Derecho de la comunicación, es una verdadera guía jurídica para aquellas personas que se dedican de manera profesional a todo lo que tenga que ver con medios y todo lo relacionado con el derecho de la información. El libro es actual y es extremadamente completo; se encuentra dividido en cinco partes: la primera hace referencia al derecho humano a la libertad de expresión y a la información; la segunda, a los límites del derecho a la información y a la libertad de expresión; la tercera habla de los derechos de los profesionales de la comunicación; la cuarta hace referencia al régimen jurídico de los medios de comunicación, y la quinta trata del régimen jurídico de la publicidad.

Es una verdadera guía porque aborda todos los temas relacionados con el derecho de la comunicación de manera sistematizada, pedagógica y comprensible, con un lenguaje simple, haciendo reflexiones desde la academia, presentando la base normativa de cada derecho o tema en particular. El trabajo presenta y explica los conceptos del derecho de la comunicación, el estatus legal de los derechos y sus límites.

Además de lo anterior, el trabajo es tan detallado que, dentro de los cinco apartados generales arriba señalados, en quince capítulos desarrolla de forma clara lo concerniente al reconocimiento constitucional de los derechos a la libertad de expresión y a la información en España; la libertad de expresión y derecho a la información en el Convenio Europeo de los Derechos del Hombre en la jurisprudencia del Tribunal Europeo de Derechos Humanos; el derecho de réplica y libertad de expresión; el derecho al honor; el derecho a la intimidad; la protección de la privacidad en Internet, el derecho de autodeterminación informativa y el derecho al olvido; el derecho a la propia imagen; el derecho del menor a una especial protección ante los medios de comunicación; el secreto profesional; la cláusula de conciencia; los derechos de autor; Internet: estatuto jurídico; régimen jurídico de la televisión; estatuto jurídico de la radio, y regulación de la publicidad.

Finalmente, otra característica del libro es que permite leer en desorden los capítulos, ya que se pueden entender de forma rápida los puntos abordados, como puede ser algún derecho, sus límites, el régimen jurídico de los medios de comunicación o la regulación de la publicidad. Por si fue- 
Esta revista forma parte del acervo de la Biblioteca Jurídica Virtual del Instituto de Investigaciones Jurídicas de la UNAM

ra poco, el libro también contiene ejemplos de casos reales en los que se involucra alguno de los temas señalados

Como la propia autora señala en el prólogo, el propósito del derecho a la comunicación "es garantizar que la comunicación, en sus diversas expresiones, encuentre su espacio" y "pueda desempeñar su función constructora de sociedad" (Azurmendi, 2016: 21). Sin duda, es un trabajo muy valioso, pedagógico, actualizado y bien hecho, que periodistas, autores, público, legisladores, jueces, ciudadanos, estudiosos del tema, entre otros, deben aprovechar.

\section{BibliogRAFía DEL LiBRo RESEÑAdo}

Azurmendi, Ana, 2016, Derecho de la comunicación. Guía jurídica para profesionales de los medios, España, Ediciones Universidad de Navarra (EUNSA). 